\title{
Understanding Social Media and Its Potentials
}

\section{Sileshie Semahagne Kumlachew, Bahir Dar University, Ethiopia}

\begin{abstract}
These days, we repeatedly hear the phrase "social media" from different sources, ranging from our nearest friends to the mass media we follow. We also hear that social media catalyzed and organized demonstrations in countries where recent revolutions broke out. But the actual role social media played in such socio-political contexts is, in most circumstances, blurred. To avert such problems, comprehending the theoretical ideals that can help us to understand such media's overall potential has a paramount significance. This paper thus aimed at assessing the theories of mediation and mediatization as alternative ways of conceptualizing the role of social media by reviewing some literatures (Schultz, 2004; Lundby, 2008; Hjarvard, 2008; Thumin, 2009; Couldry, 2008; Stromback, 2008).
\end{abstract}

Keywords: social media, media logic, mediation, mediatization 


\section{Introduction}

When the impact of the social media is raised, the groundbreaking action which happened in the Philippines in 2001 is one of the most memorable circumstances. By the time, the social media mobilized the Philippine people against their ex-president during his accusation trial, where he conspired to set aside some relevant documents. Within two hours, the information leaked through forwarded messages and reached thousands of people who in a few weeks protested and forced their president to be kicked off his power (Shirky, 2011). According to Shirky (2011), "the event marked the first time that social media had helped force out a national leader".

The recent happenings in the political discourses of the Arab and North African countries are also prime examples that witnessed the role of the social media during times of upheavals. In their attempts of toppling dictatorial governments and putting democratic elements in place, people have been extensively using social media. In some circumstances, protesters in different parts of the Arab world and North Africa could override the sophisticated and strong security networks long established by governments with the help of social media.

According to Ghannam (2011) the Arab world has been seeing the rise of an "independent vibrant" social media and steadily increasing citizen engagement on the Internet. These happenings, as he argues, are enabling the social media to "inform, mobilize, entertain, create communities, increase transparency, and seek to hold governments accountable." He also claims that examining what is going on in the social media in the Arab World may let someone to realize the "most dramatic and unprecedented improvement" in freedom of expression, association, and access to information in contemporary Arab history. Ali (2011) also put the event as follows:

The role that social media played in the Egyptian uprising is striking. Social media brought to the Egyptian people a sense of self-empowerment — through the capacity to speak and assemble - that was previously not there. Recently, social media had a similar impact in Tunisia, Libya, and Iran (p: 187).

However, there are times when people "effectively" used social media but unable to succeed. The 2006 failed Belarus activists' movement against their allegedly vote rigging President Aleksandr Lukashenko as Lukashenko became "more determined to control social media than 
ever", is a case in point (Shirky, 2011:2). Shirky (2011) also adds the 2009 Iranian Green Movement, a similar uprising against vote rigging, which failed due to "violent crackdown" by the incumbent.

From the above examples, we can infer that the social media's specific roles, if not the nature and types of the media themselves, are not clearly distinguished. The social media's increasingly complicated and intervening roles in the social, political and economic contexts throughout the world are becoming bottlenecks to scholars in their attempts to understand the roles such media can play. Comprehending the latent and covert impacts of social media over existing democratization processes and social and cultural changes as a whole is, thus, becoming increasingly complex as the media technologies and applications are being increasingly changing and as researchers dig deeper and interrogate various theoretical underpinnings related to the issue.

As a means of understanding the power of social media, so many scholars are devoting time by contextualizing and transforming the older media theoretical frameworks in to the digital age, (Lundby, 2008; Hjarvard, 2008; Thumin 2009; Couldry, 2008).

Yet, there are claims which state that conceptualizing the potentials of the social media in light of the older media theories is a farfetched phenomenon. Finnemann (2011), for example, argues that even if the extended concepts from the older media scholarships bring new insights, "they cannot be unified into one concept, and that they also lack a consistent definition of digital media". Therefore, it is the objective of this paper to scrutinize the scholarships which are used to comprehend and explain the potentials of the social media. It also asks the appropriateness of comprehending the newer media, including the social media, through the prism of the theoretical frameworks that were long developed to conceptualize the older ones.

\section{Social Media and Its Potentials in a Nutshell}

Social media is a new phenomenon that drastically transformed many aspects of mediated communication before its occurrence. Kaplan and Haenlein (2009) claim that there seems to be confusion among managers and academic researchers as to what to include within and exclude out of the term. 
In an attempt to simplify the issue at hand, Kaplan and Haenlein (2009) defined it in terms of two related concepts: Web 2.0 and User Generated Content (UGC). They describe Web 2.0 as the "beginning" of the software developers and users to use the World Wide Web as a "platform of creating and modifying" online content. Needles to say, they consider Web 2.0 as the "platform for the evolution of the social media." Using three requirements, the Organization for Economic Cooperation and Development (OECD, 2007) provided, they also described UGC as the media content forms that are "publicly available" being "created outside of professional routines" showing a sort of "creative effort". Under the prism of these ideals, then, they defined social media as follows:

Social media is a group of internet-based applications that build on the ideological and technological foundations of Web 2.0, and that allow the creation and exchange of UGC.

Tracing the definition, they further classified social media in to collaborative projects (e.g. Amazon and Wikipedia), blogs, content communities (e.g. Flick, YouTube), social networking sites (e.g. Facebook, MySpace), virtual game worlds (e.g. X-Box, play station) and virtual life worlds (e.g. Second Life). The potentials of the social media, then, entails the overall influences the aforementioned new media applications can bring about singly or in collaboration. These days, in order to understand the social media's potentials in the democratic, social and cultural spheres, a variety of diverse, overlying and sometimes contesting perspectives are on offer. These perspectives, in most circumstances, are the follow-ups of the attempts of the scholars' interrogations of the older media's potentials. In such a situation, it is problematic to put a demarcation on the theoretical frameworks of conceptualizing the new media and the traditional ones.

There are also claims that even though the new media in general and social media in particular are sharply transforming the roles and manifestations of the older media in an unprecedented manner, we are still tracing to the older media theories so as to realize the impacts of the new media. Finnemann (2011:67), for example, argued that previous theoretical underpinnings can not sufficiently support us to understand the current media phenomena as the new media opens "new trajectories" and impose the older media to transform in the "new matrix". Consequently, the term "media logic" that had been used to 
describe the impact of the independent mass media on political systems and other institutions in the $20^{\text {th }}$ century has been revised and branded as mediatization "to widen the framework by including new media and new areas of application" (Finnemann, 2011:67).

\section{Conceptualizing the Potentials of Social Media}

Social media is being expanded to the extent that everyone, who has access to computer, internet and who is skilled in using it, has the chance to easily access, upload/write and transmit messages and meet some common goals. Now, we are witnessing a number of social media sites that allow ordinary citizens to communicate with people, even with mobile phones, who share something in common (usually), everywhere in the world, fast and efficient. In such conditions, we can imagine the predicaments of figuring out the varied impacts of such communication tools.

In her case study of a "foreign reporter's blog from an area of intense conflict in Pakistan, where he was threatened by religious students", Eide (2009) implied that with the help of the new media technology, "national media events may transcend continents and be reinterpreted in very different circumstances, while the debate mainly remains constrained by national boundaries".

Eide's work is just an example that shows how the technologies are becoming powerful and how the consequences are burgeoning among geographical and abstract horizons. Yet, without seeing some theoretical perspectives that can let us comprehend the wider potentials of the social media, it would be too difficult to find out what significant and specific potential roles the social media plays alone. We can also go on asking whether there are some interwoven factors with the social media that might mislead us to oversee or underestimate the potentials of such media and whether other preconditions should exist so as to let such media play its potential; even, whether the media themselves are influenced by other intervening factors.

We can also imagine how problematic it would be to conceptualize the potentials of the social media in other parts of the world, like Denmark and Norway, where access to the Internet and computer and media literacy are very high and let the citizens to have extensive applications of social media. This is because the likelihood of participation and use of the social media in 
such countries is so extensive that it will be more complex to theorize the power of the media in light of its social, cultural and political implications. It is under this point of view that a few theoretical ideals pop up in the current academic scenario related to the issue.

Of the scholarly debates in the attempt to conceptualize the potentials of the social media, the theories of mediatization and mediation are becoming increasingly attention-grabbing. Some scholars choose the one over the other. Others prefer to use both to understand the potentials of the media.

\section{Scrutinizing Mediatization and Mediation in Theorizing Social Media's Potentials}

Stromback (2008) defined mediatization as a "multidimensional and inherently processoriented" concept that is increasingly adopting politics and changes the important issue from the "independence of the media from politics and society" to the "independence of politics and society from the media." Mediatization has also been used to accommodate the "dominant" role of the media as "providers of cultural products and beliefs" (Hjarvard, 2008). Delimited in the Western democracies after World War II, Stromback (2008) provided four distinct phases of mediatization in order to better conceptualize the role of the media, including the Internet. Accordingly, the first phase, which he calls "prerequisite" for the remaining three successive mediatization phases, embraces "the most important information and channel of communication" between the citizenry and political institutions and actors, such as political parties, governmental agencies, or political interest groups. In the second phase, he puts the independence of the media from the influence of political institutions and the production of contents by their own; but still, the media are not totally independent entities as they may have influence sometimes in content. In his third classification, he narrates the media as more independent that are able to adopt the politicians than subscribing to them. At this stage, the media are increasingly becoming "integral parts of even the policymaking processes". Therefore, political and social actors will develop ideals from the media and apply that to the real socio-political arenas. Stromback (2008) puts it:

At this point, the distinction between the media world - the depictions of reality shaped by the media logic, and which people have to rely on when forming opinions and attitudes - and the real world, as it is objectively shaped or played out, begins to lose its significance. The mediated reality becomes more important than the actual reality, in the sense that it is the mediated reality that people have access to and react to (Stromback, 2008:238). 
This analogy can be more comprehended with the "misrepresentations" (Michira 2002) of Africa in the Western media via the Internet, television programs, documentaries and the movie industry. According to Michira (2002), Africa, while it comprises of 54 different countries, is misrepresented by the Western media as if it were a "homogenous entity" characterized by "primeval irrationality, tribal anarchy, civil war, political instability, flagrant corruption, incompetent leadership and managerial ineptitude, hunger, famine and starvation as well as rampant diseases, especially AIDS." This argument signifies the potential of the media to override the "actual reality" (Stromback, 2008).

Stromback's final classification is when the media is not only adopted but also "internalized" by the social actors including ordinary citizens, and politicians. Hjarvard (2008) confirms the above classifications by referring mediatization to a "more long-lasting process, whereby social and cultural institutions and modes of interaction are changed as a consequence of the growth of the media's influence." He argues that the media do not only play a role of their own willpower, but also as an independent institution providing the means by which other social institutions and actors communicate in such a way that the media "intervene into, and influence the activity of other institutions, such as the family, politics, organized religion, etc.," while they also provide interaction platforms for society as a whole.

The concept of mediatization is also contended to sustain, if not prosper, in the age of the new media. By viewing the claim in to three scholarly perspectives, which he named skeptical, moderate and optimistic, Schultz (2004) concluded that mediatization is "applicable to all kinds of media, old and new". The process of globalization is also expanding the use of mediatization in wider territories, out of the Western democracies. As new media is steadily expanding and substituting, and sometimes transforming, the traditional means of communication, the manifestation of mediatization is being transformed in to a newer and more complex perspective. Hjarvard (2008) argues that though the influence of what mediatization exerts may vary, more and more regions and cultures will be affected as globalization progresses use and help the existence of the process as a prerequisite and corequisite, respectively, to "extend communication and interaction over long distances" and to institutionalize "mediated communication and interaction in many new contexts." 
Thus, we can see how the process is diverging at the expense of the boom in the media technology and its increasing expansion to new geographical, social, political and cultural contexts. It is worth mentioning the classification of Schultz (2004) in order to better understand and elaborate the process of mediatization in the changes generated by the new media. He classified the different aspects of change in the process of mediatization into four important categories. These are: extension ("the media extend the natural limits of human communication capacities"), substitution ("the media substitute social activities and social institutions"), amalgamation ("media amalgamate with various non-media activities in social life") and accommodation ("the actors and organizations of all sectors of society accommodate to the media logic").

This classification is, however, questioned by Couldry (2008) who views it as "an indirect confirmation" of the "linear nature" of the mediatization thesis. He raised the notion of substitution (Schultz 2004), as an example, and asks, "how else can we understand substitution, which implies that one state of affairs has become another because of the intervention of a new element (media)?" He also contends that there is an attempt to "cover transformations that go far beyond the adoption of media forms or formats to the broader consequences of dependence upon media exposure" when such transformations should be scrutinized under other theoretical contexts.

Couldry (2008), thus, prioritizes mediation than mediatization. Mediation, for him, is "the overall effect of media institutions existing in contemporary societies, the overall difference that media make by being there in our social world." He further argues that he prefers mediation to better grasp the complexity of "the multiple" and "often dialectical" processes through which the range of practices that we gather under the new media, specifically referring 'digital storytelling'-which he defined as “online personal narrative formats that have recently become prevalent”, like MySpace, Facebook, blogs and YouTube.

As to Lundby (2008), Couldry's claim of "linear nature" of the mediatization narration is also a "bit one-eyed" as he relates Hjarvard's explanation of mediatization in to a narrow context. Lundby (2008) contends that Hjarvard (2007: 3) cited in Lundby (2008) incorporated "organizational, technological, and aesthetic functioning including the ways in which media allocate material and symbolic resources and work through formal and informal rules" in the 
mediatization context. On the other hand, Lundby (2008) also critiqued Hjavard himself for "minimizing" the meaning of mediation in to "communication and interaction through a medium in a particular setting, where the message and the relation between sender and receiver may be affected" while Hjavard (2007: 3-4) cited in Lundby (2008) grasps that "mediation focus on how the media influence both message and relation between sender and receiver". Mediatization, for Lundby (2008) is the "transformation of processes in to forms or formats suitable for media re-presentation." He, thus, claimed that the problem with the definition of the one over the other lies on the notion of "representations".

In a wider context, Silverstone (2005: 189) cited in Lundby (2008) defined mediation as the entire surrounded institutional and technological "transformative processes" where the institutions, and technologies as well as the meanings that are delivered are "mediated in the social processes of reception and consumption". Lundby (2008) then concludes that mediation in a broader sense deals with "the same transformation process" with "broad mediatization", which he defined as "a long term process through which core elements of a social or cultural activity assume media”.

\section{Summary}

Beginning with anecdotes of successful and failed stories of political movements that involved the application of some social media, this paper delimits its purview into the theoretical underpinnings that lie behind the potentials of social media in the processes of democratization, social and cultural change. This paper also makes clear that social media is a broad term that accommodates the application of "Web 2.0" that entertains the "creation and exchange of user generated content" (Kaplan and Haenlein, 2009).

It has also reviewed the scholarships that are developed in the processes of comprehending the potentials of social media in the democratization, social and cultural spheres. It has particularly focused on mediation and mediatization. Eventually, it has been found out that the broader definitions given for both concepts, by different researchers, talks about the same "transformative processes"- the entire surrounded institutional and technological processes where the institutions, and technologies as well as the meanings that are delivered are "mediated in the social processes of reception and consumption" (Lundby, 2008). 


\section{References}

Benmayor, Rina (2008): Digital storytelling as signature pedagogy for the new humanities. Arts and Humanities in Higher Education, 7, 188-205.

Couldry, Nick (2008): Mediatization or mediation? Alternative Understandings of the Emergent Space of Digital Storytelling.New Media and Society, Vol. 10(3), 373-391. Finnemann, Niels O. (2011): Mediatization theory and digital media.Communications, Vol. 36(1):67-89.

Hjarvard, Stig (2007): "Changing media- Changing language. The mediatization of society and the spread of English and Medialects”, in Lundby, Knut (ed.): Digital storytelling, mediatized stories. Self-representations in New Media. New York: Peter Lang Publishing, 1-20.

Hjarvard, Stig (2008) The mediatization of society: A theory of media as agents of social and cultural change. Nordicom Review. Vol. 29(2):105-134.

Kaplan, Andreas M., Haenlein Michael (2010): Users of the world unite! The challenges and opportunities of social media. Business Horizons. Vol. 53 (1), 59-68.

Lundby, Knut (2008): “Introduction: Digital storytelling, mediatized stories”, in Lundby,

Knut (ED.): Digital storytelling, mediatized stories. Self-representations in New Media. New York: Peter Lang Publishing. 1-20

Schultz, Winfried (2004): Reconstructing mediatization as an analytical concept. European Journal of Communication. Vol. 19(1):87-101.

StrömbäckJesper( 2008): Four phases of mediatization: an analysis of the mediatization of politics. The International Journal of Press/Politics13 (3), 228-246.

Thumin, Nancy (2008): “'It's good for them to know my story’: Cultural mediation as tension”, in Lundby, Knut (ed.): Digital storytelling, mediatized stories. Selfrepresentations in New Media. New York: Peter Lang Publishing, 85-104.

Silverstone, Roger (2005) "The sociology of mediation and communication. In Lundby, Knut (ed.): Digital storytelling, mediatized stories: Self-representations in New Media. New York: Peter Lang Publishing, 1-20.

Thompson, John B (1990): Ideology and modern culture? In Hjarvard, Stig (2008): The mediatization of society. A theory of media as agents of social and cultural change. Nordicom Review, Vol. 29(2):105-134. 


\section{Web References}

Clay Shirky (2011): "The political power of social media". http://www.gpia.info/files/u1392/Shirky_Political_Poewr_of_Social_Media.pdf

Ghannam, Jeffery (2011): "Social media in the Arab World: Leading up to the uprisings of 2011."

http://www.hirondelle.org/wpcontent/uploads/2011/03/SocialMediaintheArabWorldCIMA2011.pdf

Michira, James (2002): "Images of Africa in the Western media." http://www.teachingliterature.org/teachingliterature/pdf/multi/images_of_africa_michi ra.pdf

Srinivasan, Ramesh (2006): "Indigenous, ethnic and cultural articulations of new media" http://ics.sagepub.com/cgi/content/abstract/9/4/497

Sawhney, Nitin (2009): "Voices beyond walls: The role of digital storytelling for empowering marginalized youth in refugee camps". http://www.fotocomp.it/officina/IDC2009/media/workshops.pdf/P302-Sawhney.pdf

Eide, Elisabeth: "Global divides and transnational media literacy". http://www.nordicom.gu.se/common/publ_pdf/283_eide.pdf 